\title{
Assessment of DNA Damage of Periodontal Tissues in Premalignant Condition: By Comet Assay
}

\author{
Anubha M Raj ${ }^{1}$, Surekha Rathod ${ }^{2}$, Abhay P Kolte ${ }^{3}$, Pranjali V Bawankar ${ }^{4}$
}

\begin{abstract}
Aim and objective: The present study aimed to determine the effect of OSMF on periodontium and DNA damage in affected and healthy subjects. Materials and methods: Sixty patients (20 patients with OSMF and periodontitis, 20 patients having only OSMF, and 20 controls) were examined clinically with regard to probing pocket depth (PPD), clinical attachment level (CAL), and gingival recession (GR). Radiovisiographs were obtained for the assessment of alveolar bone level. Comet assay was used for the assessment of DNA damage by evaluating tail length, percentage of DNA in the tail, and olive tail moment.

Results: Mean PPD, CAL, and GR of patients having both OSMF and periodontitis were $4.21,5.75$, and $1.6 \mathrm{~mm}$, respectively, which was significantly higher than PPD, CAL, and GR of the other two groups. The mean alveolar bone loss was 5.94, 0.57 , and $0.51 \mathrm{~mm}$ for groups I, II, and III, respectively. Mean tail DNA percent was 49.77, 44.55, and 11.01 and the olive tail moment was 14.16, 12.12, and 2.50 for groups I, II, and III, respectively. The mean tail parameters for the OSMF population were significantly higher than healthy group.

Conclusion: OSMF was found to have an adverse effect on periodontal tissue and the severity of DNA damage was more in patients having OSMF with periodontitis.

Clinical significance: Comet assay is a noninvasive, rapid, and inexpensive indicator for the assessment of DNA damage in periodontal tissue of OSMF patients with periodontitis.

Keywords: DNA, Oral submucous fibrosis, Periodontitis, Premalignant lesions.

World Journal of Dentistry (2021): 10.5005/jp-journals-10015-1850
\end{abstract}

\section{INTRODUCTION}

Oral submucous fibrosis is a chronic disorder commonly occurring in individuals of Asian origin. It is progressive in nature affecting the oral tissues such as buccal mucosa, soft palate, tongue, and lips along with the pharynx and parts of the esophagus. It clinically manifests as the aggravating fibrosis of the tissues leading to limitations in the mouth opening. Other features included extreme sensitivity to hot and spicy food, stiffness of the lips, tongue, and palate which ultimately negatively influence the overall quality of the patient's life. ${ }^{1,2}$

It is a precancerous condition with $1 \%$ malignant transformation risk and is attributed to multifactorial etiopathogenesis comprising consumption of chilies, tobacco and areca nut, genetic factors, nutritional deficiencies, and autoimmunity. ${ }^{3-7}$ A large numbers of studies in the literature suggest and confirm arecoline in areca nut as one of the primary etiological agents. ${ }^{8,9}$ As a result of a disturbance in the equilibrium of matrix metalloproteinase level and its inhibitors, the deposition of the extracellular matrix increases, which ultimately increases the susceptibility of this condition. This is mainly because collagen which are major structural components of the extracellular matrix is deposited excessively in addition to their decreased degradation. There is a different mechanism through which areca nut or betel quid, the main etiological factor of OSMF, affects the periodontium. Areca nut extract is supposed to reduce the antibacterial activity and superoxide anion production of neutrophil and explains the reason for the less efficient elimination of bacteria from the periodontal environment. Thus, the inhibition of the antimicrobial function of neutrophils may alter the microbial ecology of the oral cavity, and this may be one of the possible mechanisms by which areca nut compromises the oral health of users who consumed areca nut products.

\begin{abstract}
${ }^{1-4}$ Department of Periodontics and Implantology, VSPM Dental College and Research Centre, Nagpur, Maharashtra, India

Corresponding Author: Surekha Rathod, Department of Periodontics and Implantology, VSPM Dental College and Research Centre, Nagpur, Maharashtra, India, Phone: +91 9011071477, e-mail: drsurekhar@ hmail.com
\end{abstract}

How to cite this article: Raj AM, Rathod S, Kolte AP, et al. Assessment of DNA Damage of Periodontal Tissues in Premalignant Condition: By Comet Assay. World J Dent 2021;12(4):316-321.

Source of support: Nil

Conflict of interest: None

Preliminary investigations suggest that areca nut extract may have a deleterious effect on periodontal health by regulating the apoptotic pathways in neutrophils. ${ }^{10}$ In addition, it is revealing that areca nut chewers exhibit a higher prevalence of gingival and periodontal diseases even after the removal of local deposits such as plaque and calculus. Areca nut is thought to interfere with microbial mechanisms of the defense cells such as neutrophil, thus promoting the accumulation of periodontopathic bacteria and suppression of several normal commensal microbes. This cumulative influence leads to an increased predisposition to the disease and severity of destruction within the tissue..$^{11,12}$

In addition, reactive oxygen species (ROS) through the pathogenic mechanism of DNA damage, lipid peroxidation, disruption of proteins, and inflammatory cytokines cause structural alteration in the mitochondria contributing to tissue destruction. ${ }^{13,14}$ The comet assay or single-cell gel electrophoresis is a novel very sensitive fluorescent microscopic method widely recognized 
for quantitating DNA damage and repair in eukaryotic cells and some prokaryotic cells. This technique is a noninvasive, rapid, and inexpensive way to study factors modifying mutagenicity and carcinogenicity. Because of its unique design, it is possible to determine whether all cells in a population show the same degree of damage or whether there is a heterogeneous response to the genotoxic insult. The name of the assay comes from the image of the electrophoresis gel which resembles a "comet" with a distinct head and tail. The cell with DNA damage appears in the form of a "comet" while the undamaged cell appears as a halo. The head is composed of intact DNA, while the tail consists of damaged (singlestrand or double-strand breaks) or broken pieces of DNA. ${ }^{2}$

The literature search revealed limited information on the concomitant effects of oral submucous fibrosis on the periodontal tissues, even though they are subjected to continuous insults and protracted exposure to the areca nut extracts. Under such circumstances, it is prudent to examine these effects in the periodontal structures and the associated DNA damage, if any. So, this study aimed to evaluate and compare the effect of OSMF on adjacent periodontal tissues and measure the DNA damage by comet assay in periodontally healthy without OSMF and chronic periodontitis wand OSMF patients with and without chronic periodontitis.

\section{Materials and Methods}

The present study comprised a total of 60 patients within the age range of 15-45 years from those visiting the Department of Periodontics and Implantology. The study was approved by the institutional ethics committee of our institute.

The patients were equally divided into the following three groups. Group I $(n=20)$ patients diagnosed with OSMF and periodontitis, group II $(n=20)$ patients diagnosed with OSMF and were periodontally healthy, and group III $(n=20)$ patient without OSMF and periodontally healthy patients of all stages of OSMF were included in the study according to Khanna's classification. Periodontitis was classified according to the classification given by Armitage. ${ }^{15}$ The inclusion criteria for group I were probing pocket depth (PPD) $\geq 5 \mathrm{~mm}$, clinical attachment level (CAL) $\geq 5 \mathrm{~mm}$, and habit of chewing gutkha (betel nut quid) for at least 5 years and $>5$ times a day. For group II, periodontal parameters are same as group I and without habit of gutkha.

Diagnosis of OSMF was done by a single examiner (AR) based on the classification given by Khanna JN and Andrade NN (1995). ${ }^{16}$

A detailed account of personal medical and dental history with the clinical finding was recorded in a specifically designed case history pro forma for every patient. The patients were briefed about the study protocol and written consent for participation was obtained from them. The study was initiated after clearance from the Institutional Ethics Committee.

The sample size was calculated based on the study by Dodani et al. They reported a mean comet tail length of 4.9 (1.07) for normal group and $1.49(0.38)$ for case group. This resulted into an effect size of 4.33. However, we targeted a smaller effect size difference of 1.0 and to detect this difference using $t$-test for independent samples with $95 \%$ confidence and $80 \%$ power the resulting sample size obtained was 34 with 17 samples per group.

Patients adhered to the strict inclusion criteria and were excluded if they were suffering from diabetes mellitus, arthritis, and a history of receiving antibiotics, cytotoxic agents, NSAIDs, or periodontal therapy in the past 6 months. Pregnant or lactating women, smokers, alcoholics, and any other oral lesions such as ulcers or premalignant or malignant lesions were excluded from the study.

\section{Clinical Parameters}

Assessment of the periodontal clinical condition of the patients was done with the recording of PPD, CAL, and gingival recession (GR) which are measured using William's graduated periodontal probe (Hu-Friedy, Chicago, IL) on four sites of each tooth. Plaque index (PI) and gingival index (GI) were also recorded. ${ }^{17,18}$ Radiographic assessments were done with radiovisiographs in which the distance from cement-enamel junction to alveolar bone crest (CEJ-ABC) with commercially available software (DIGORA Optime RVG Software, Finland) DIGORAtm optime RVG software, Finland. All the clinical, radiographic, and DNA damage measurements were performed by separate examiners (AR and SR) who were blinded to the other measurements and were calibrated in a pilot study.

\section{DNA Damage Parameters}

DNA damage was assessed by OxiSelect ${ }^{\mathrm{TM}}$ Comet Assay Control Cells kit for this gingival epithelial cells were obtained by wooden spatula on attach gingiva. A disposable sterile interproximal brush (STIM interproxbruhes, DHOT-AIBS, New Delhi, India) was used for collection of gingival epithelial cells in each patient. The brush was used to gently scrape over the marginal and attached gingiva and the cells were collected in microcentrifuge tube (Eppendrof tubes, Eppendrof, Hansburg, Germany) which contain phosphate-buffered saline solution. Evaluation of the gingival epithelial cells under the Comet Assay protocol was done as per procedure notified. ${ }^{19}$ For visualization of DNA damage epifluorescence microcopy with FITC filter at $40 \times$ magnification was used. The recording of tail length, tail moment, and percentage DNA in tail was considered. Tail parameters were evaluated according to OXISELECT ${ }^{\mathrm{TM}}$ Comet Assay protocols using automated software. The different measurements were done as follows:

Tail DNA $\%=100 \times$ Tail DNA Intensity / Cell DDNA intensity.

Tail moment $=$ Tail DNA $\% \times$ Tail moment length

(Tail moment length was measured in pixel from the center of the head to the center of the tail).

\section{Statistical Analysis}

Data on periodontitis parameters on patients from three groups, i.e., OSMF with periodontitis, OSMF, and normal groups were obtained. Summary statistics like mean, standard deviation, and median were obtained for each parameter in three groups. The difference in the mean parameter values across groups was tested for statistical significance using one-way analysis of variance (ANOVA). Furthermore, pair-wise comparisons were performed using Tukey's post hoc test. Correlation of different periodontitis parameters with frequency and duration were obtained separately for OSMF with periodontitis and OSMF groups. Descriptive statistics for parameters were also obtained according to stages in these two groups. The comparison of tail parameters across groups was performed using one-way ANOVA. Correlation of PD was performed with tail parameters. Moreover, the comparison of tail parameters was done between pooled OSMF with periodontitis and OSMF groups and the normal group using $t$-test for independent samples. The comparison of PD, GR, and CAL parameters was done between regional and OSMF with periodontitis as well as regional and OSMF 


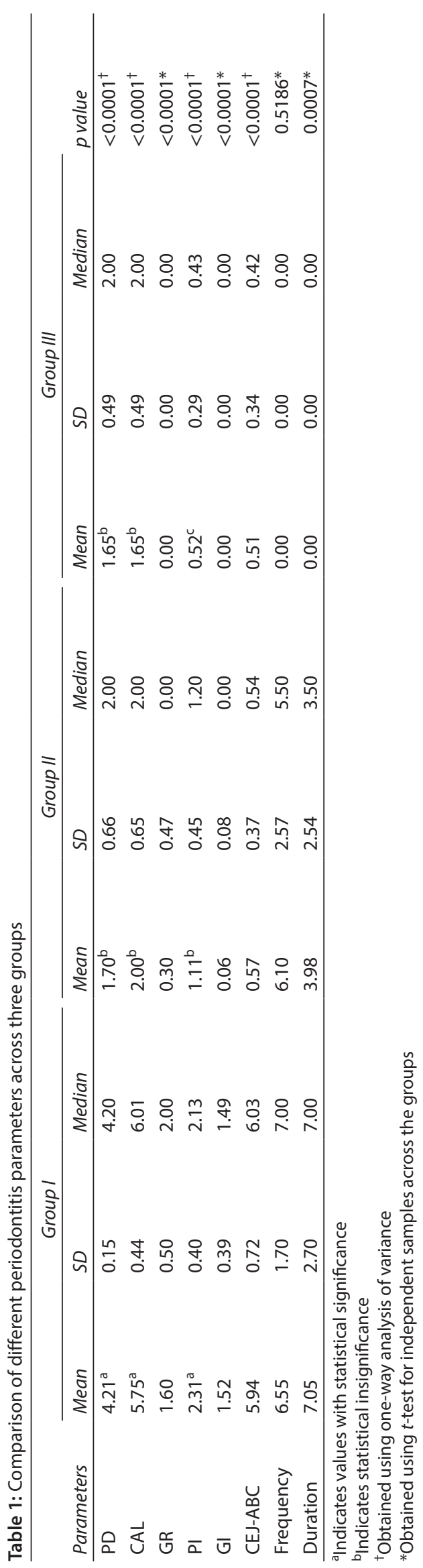

groups. Furthermore, the comparison of parameters was also done across regions.

\section{Results}

On comparison of different periodontal parameters across three groups, mean PD, CAL, PI, GI, and distance CEJ-ABC of group I was $4.21 \mathrm{~mm}, 5.75 \mathrm{~mm}, 2.31 \mathrm{~mm}, 1.52 \mathrm{~mm}$, and $5.94 \mathrm{~mm}$, respectively, which was significantly higher than $1.70 \mathrm{~mm}, 2 \mathrm{~mm}, 1.1 \mathrm{~mm}, 0.6$ $\mathrm{mm}$, and $0.57 \mathrm{~mm}$ of group II, respectively. However, there was no statistically significant difference between the periodontal parameters of group II and group III (Table 1). The overall mean GR in group I was $1.60 \mathrm{~mm}$, while in group II was $0.30 \mathrm{~mm}$. The difference between the means was highly significant (Table 1). Mean duration of OSMF for group I was $7.05 \pm 2.7$ years which was significantly higher compared with group II, having mean duration of $3.98 \pm 2.54$ years.

The mean GR where quid was placed (regional) for group I was $2.3 \mathrm{~mm}$ which was significantly higher than group II which was 1.25 $\mathrm{mm}$ (Table 2). Among the group I mean localized GR was $2.3 \mathrm{~mm}$ which was significantly higher than the overall $G R$ value, i.e., 1.6 $\mathrm{mm}$. Similar was the result with group II where the mean localized GR was $1.2 \mathrm{~mm}$ which was significantly higher than the overall GR value, i.e., $0.3 \mathrm{~mm}$ (Table 2 ).

\section{Comet Assay Analysis}

Mean tail length, tail moment, and tail DNA percent of group I were $36.10,14.16$, and 49.77 , respectively (Fig. 1), which was significantly higher than group III, which were $7.8,2.5$, and 11.01, respectively (Fig. 2). Mean tail length, tail moment, and tail DNA percent of group II (Fig. 3) were 33.64, 12.12, and 44.55, which were significantly higher than that of group III. However, there was no statistically significant difference between tail parameters of group I and group II (Table 3). When tail parameters of all OSMF patients (with and without periodontitis) were compared with healthy group then mean tail length, tail moment, and tail DNA percent of OSMF subjects was significantly higher than that of group III patients.

\section{Discussion}

Single-cell gel electrophoresis (SCGE) or "comet assay" is a rapid and very sensitive fluorescent microscopic method for detecting various forms of DNA damage at the individual cell level. According to epidemiological studies, betel quid chewing is one of the popular habits of Southeast Asia and about 600 million people chew areca nut ${ }^{20}$ and are associated with oral submucous fibrosis. Studies show that there is a higher prevalence of the periodontal disease among consumers of betel nut when compared with non-consumers. ${ }^{21}$

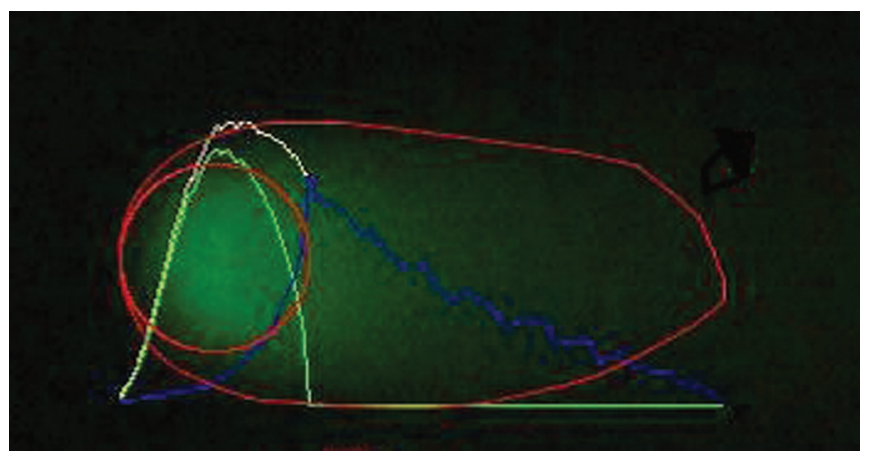

Fig. 1: Comet assay image representing head and tail of comet for damaged DNA in group I with FITC filter at 40× magnification 


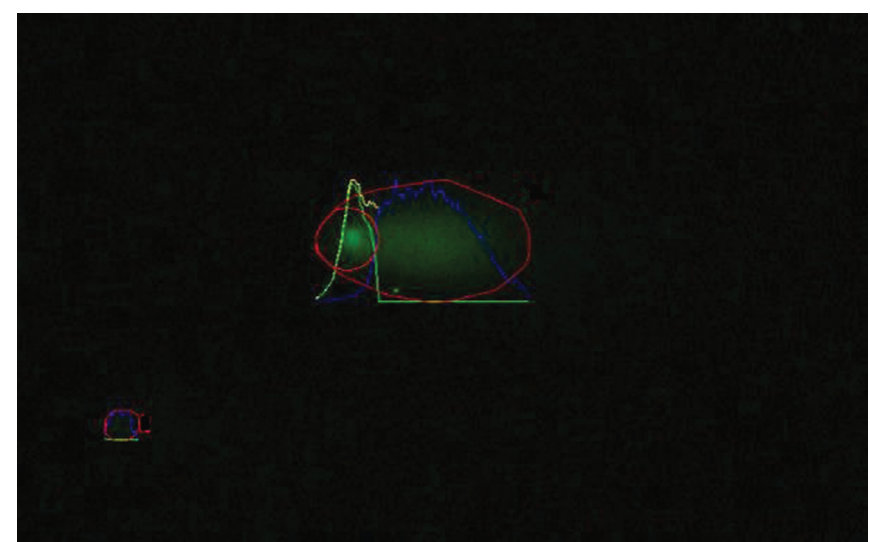

Fig. 2: Comet assay image representing head and tail of comet for damaged DNA in group II FITC filter at $40 \times$ magnification

Table 2: Comparison of gingival recession between regional (site of quid placement) and the overall site in group I and group II

\begin{tabular}{llcll}
\hline & & GR & \multicolumn{2}{c}{$p$ value } \\
\hline Group I & Regional & $2.3 \pm 0.47$ & $<0.0001$ & $<0.0001^{*}$ \\
& OSMF + & $1.6 \pm 0.5$ & & \\
& periodontitis & & & \\
Group II & Regional & $1.25 \pm 0.44$ & $<0.0001$ & \\
& OSMF & $0.3 \pm 0.47$ & & \\
\hline
\end{tabular}

*Obtained using $t$-test for independent samples

Also, subjects with the habit of areca nut, betel nut, or tobacco chewing are associated with a high prevalence of bleeding on probing and high clinical levels of periodontal infections with periodontopathogens, and are prone to increased risk of chronic periodontitis.

Arecoline is the main areca alkaloid in the areca nut which inhibits the growth, attachment spreading, migration, and collagen synthesis of human gingival fibroblast. Apart from that it also impairs the activity of inflammatory markers which describes its role in periodontal disease. ${ }^{22}$

Both periodontitis and OSMF are evidenced to possess DNA damage due to different mechanisms. Like in periodontitis overproduction of ROS may lead to premature oxidative DNA damage. ${ }^{23}$ In 1992, study performed by Sundqvist et al. confirmed the toxic effect of areca-nut on oral epithelial cells by DNA singlestrand breakage. Arecoline, a major areca-nut alkaloid, is reported to cause the DNA damage IN in OSMF due to its chromosomal breaking ability. ${ }^{24}$

The present study adds to the understanding of the link between OSMF and periodontal disease with information regarding DNA damage. The mean of PD and CAL in subjects of group I was significantly higher than group II showing more severity of periodontal disease. However, value of probing depth and CAL of group II was higher than group III but the difference was statistically non-significant. The result of present study is in accordance with study conducted by Akhter et al., ${ }^{25}$ who reported that betel quid chewers exhibited higher mean PD and CAL. Similarly, Ling et al. in $2001^{26}$ found positive relation between habit of betel quid chewing and severity of periodontal destruction.

In contrary to Dodani et al., we have found non-significant difference for PD and CAL of OSMF patients without periodontitis and healthy subjects. These variations in the findings can be attributed to the selection of the patients. ${ }^{2}$

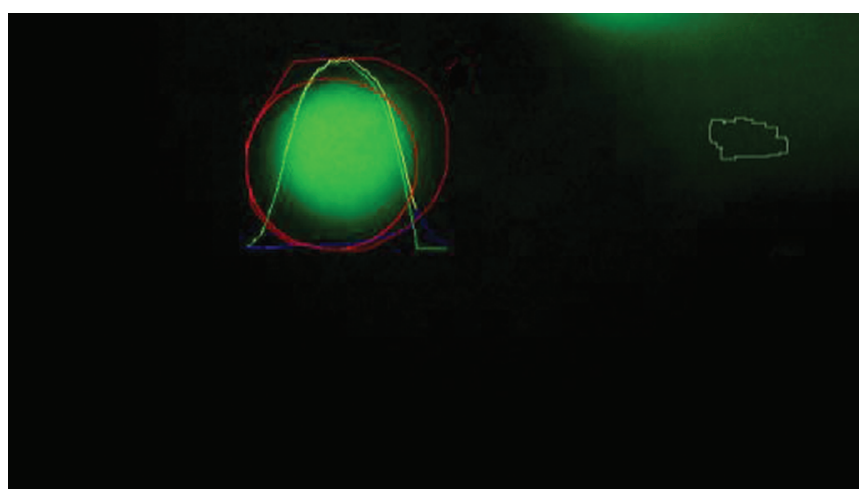

Fig. 3: Comet assay image representing healthy DNA in group III FITC filter at $40 \times$ magnification

When compared between group I and group II, mean values for PD and CAL were significantly higher for group I, also longer duration of betel quid chewing habit was found in group I than group II possibly showing the time-dependent deleterious effect of betel nut on gingival tissue. Reichart et al. found a strong correlation between the duration and frequency of betel quid used per day and the presence of oral mucosal lesions but periodontal status was not examined. ${ }^{27}$

The present study corroborates the findings of Akhter et al. in which significant associations of betel quid additives were established with periodontal disease and dose-response effects (frequency and duration) of betel quid chewing. ${ }^{25}$ It was found that the concentration of arecoline in saliva during betel quid chewing was about $140 \mu \mathrm{g} / \mathrm{mL}$ and Wyk et al. found inhibition of growth of human buccal mucosa fibroblasts at $50-150 \mu \mathrm{g} / \mathrm{mL}$ concentrations of arecoline. ${ }^{28}$

Despite having an almost similar frequency of quid intake for group I and group II, periodontal destruction was more in group I. This could be attributed to the longer duration of habit and other variables like concentration/amount of areca nut, mode by which subjects keep quid in mouth and for how many minutes they kept the quid in the mouth which was not recorded.

Similar was the result of the distance between CEJ-ABC and GR. Group I showed highest distance and GR value among all the groups and no significant difference between group II and group III. However, significant observation which was found in current study was that place or site where quid was placed showed greater value of GR than the overall GR value for the same individual. Reason for this could be a mechanical trauma. ${ }^{29}$ Martinez et al. observed that for every year of exposure to tobacco, loss of attachment irrespective of oral hygiene or other socioeconomic status and attributed to continuous mechanical trauma of tobacco component for longer duration. ${ }^{30}$

Also, according to Axell and Poulson et al., GR depends on the duration of the habit and the amount and type of snuff and are found to be more frequent among users of loose snuff when compared with users of portion-bag-packed snuff. 31,32

It is suggested that genetic damage has an important role in various chronic inflammatory and degenerative diseases. The role of chromosomal instability in the predisposition of these diseases has been evaluated with the help of cytogenetic tests. So, in the current study, another important parameter was considered as an assessment of DNA damage by comet assay. In the current study, tail parameters such as tail length, olive tail moment, and 


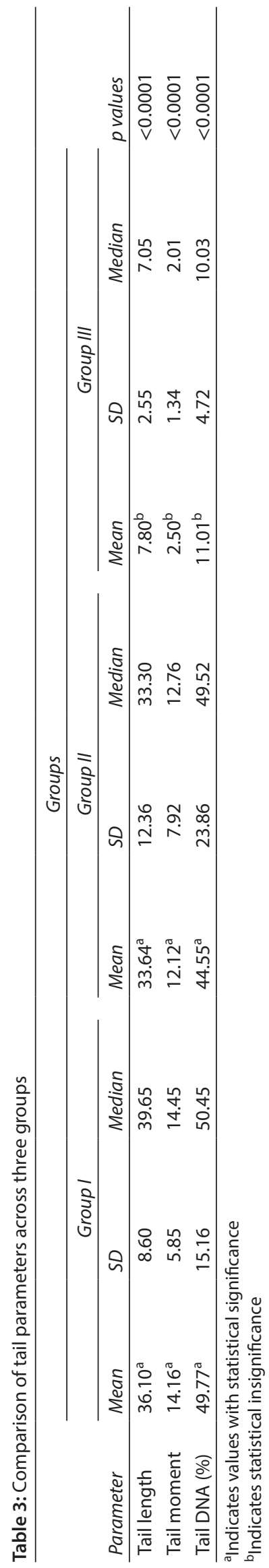

percentage of DNA in the tail were taken for the assessment of DNA damage. ${ }^{33}$ Results of the present study were in accordance with a study conducted by Dodani et al. in $2012^{2}$ where authors found significantly higher tail length in the test group when compared with tail length of healthy group II, but the values of tail length obtained in their study were different from that of the current study.

Variation in the measured values for tail length can be attributed to the fact that measurement by digital software gives more accurate readings of what we have used than manual calculations which were used by Dodani et al. ${ }^{2}$

DNA damage was found in both group I and group II but severity of DNA damage although not significant but was more in group I, which comprised patients with OSMF having periodontitis, showing possible association between OSMF and periodontitis reflected through analysis of Comet Assay. Cause and effect relationship cannot be established as it is an observational study. Multicenter clinical trials with larger sample size are needed to prove the mechanistic relationship between DNA damage and periodontitis if any. Low sample size, mode, frequency, and time of quid placement were not evaluated are some of the limitations of the study.

\section{Conclusion}

Observations of the current study illustrate that OSMF leads to more recession and bone destruction which is site-specific and habit-dependent and also projects DNA damage as one of the markers to determine cytogenic damage in periodontal disease. The combined effect of OSMF and periodontitis increases the risk for the destruction of oral mucosal and gingival tissue which needs to be diagnosed earlier.

\section{Acknowledgment}

The authors would like to thank the Department of Anatomy and Histology, NKP Salve Institute of Medical Sciences, Nagpur for providing the necessary aids to carry out this research.

\section{References}

1. Ekanayaka RP, Tilakaratne WM. Oral submucous fibrosis: review on mechanisms of malignant transformation. Oral Surg Oral Med Oral Pathol Oral Radiol 2016;122(2):192-199. DOI: 10.1016/j. oooo.2015.12.018.

2. Dodani K, Anumala N, Avula H, et al. Periodontal findings in patients with oral submucous fibrosis and comet assay of affected gingival epithelial cells. J Periodontol 2012;83(8):1038-1047. DOI: 10.1902/ jop.2011.110352.

3. Sirsat SM, Khanolkar VR. Submucous fibrosis of the palate in diet preconditioned wister rats Induction by local painting of capsaicin - an optical and electron microscopic study. Arch Patho 1960;170:171179.

4. Murti PR, Bhonsle RB, Gupta PC, et al. Etiology of oral submucous fibrosis with special reference to the role of areca nut chewing. J Oral Pathol Med 1995;24(4):145-152. DOI: 10.1111/j.1600-0714.1995. tb01156.x.

5. Chiu CJ, Chiang CP, Chang ML, et al. Association between genetic polymorphism of tumor necrosis factor-alpha and risk of oral submucous fibrosis, a precancerous condition of oral cancer. J Dent Res 2001;80(12):2055-2059. DOI: 10.1177/00220345010800120601.

6. Oliver AJ, Radden BG. Oral submucous fibrosis. Case report and review of the literature. Aust Dent J. 1992;37(1):31-34. DOI: 10.1111/j.18347819.1992.tb00830.x.

7. Canniff JP, Harvey W, Harris M. Oral submucous fibrosis: its pathogenesis and management. Br Dent J 1986;160(12):429-434. DOI: 10.1038/sj.bdj.4805876. 
8. Hazarey VK, Erlewad DM, Mundhe KA, et al. Oral submucous fibrosis: study of 1000 cases from central India. J Oral Pathol Med 2007;36(1):12-17. DOI: 10.1111/j.1600-0714.2006.00485.x.

9. Ariyawardana A, Athukorala AD, Arulanandam A. Effect of betel chewing, tobacco smoking and alcohol consumption on oral submucous fibrosis: a case-control study in Sri Lanka. Oral Pathol Med. 2006;35(4):197-201. DOI: 10.1111/j.1600-0714.2006.00400.x.

10. Ho WH, Lee $Y Y, C$ hang $L Y$, et al. Effects of areca nut extract on the apoptosis pathways in human neutrophils. J Periodont Res. 2010;45(3):412-420. DOI: 10.1111/j.1600-0765.2009.01253.x.

11. de Miranda CM, van Wyk CW, van der Biji P, et al. The effect of areca nut on salivary and selected oral microorganisms. Int Dent J 1996;46(4):350-356.

12. Hung $\mathrm{SL}$, Chen $\mathrm{YL}$, Wan $\mathrm{HC}$, et al. Effects of areca nut extracts on the functions of human neutrophils in vitro. J Periodontal Res 2000;35(4):186-193. DOI: 10.1034/j.1600-0765.2000.035004186.x.

13. Waddington RJ, Moseley R, Embery G. Reactive oxygen species: a potential role in pathogenesis of periodontal diseases. Oral Dis 2000;6(3):138-151. DOI: 10.1111/j.1601-0825.2000.tb00325.x.

14. Govindaraj P, Khan NA, Gopalakrishna P, et al. Mitochondrial dysfunctionand genetic heterogeneity in chronic periodontitis. Mitochondrion. 2011;11(3):504-512. DOI: 10.1016/j.mito.2011. 01.009 .

15. Armitage GC. Development of a classification system for periodontal diseases and conditions. Ann Periodontol. 1999;4(1):1-6. DOI: 10.1902/ annals.1999.4.1.1.

16. Khanna JN, Andrade NN. Oral submucous fibrosis: A new concept in surgical management. Int J Oral Maxillofac Surg 1995;24:433-439.

17. Turesky S, Gilmore ND, Glickman I, et al. Reduced plaque formation by the chloromethyl analogue of vitamin C. J Periodontol 1970;41(1):4143. DOI: 10.1902/jop.1970.41.41.41.

18. Loe H, Silness J. Periodontal disease in pregnancy: Prevalence and severity. Acta Odontol Scand 1963;21(6):533-551. DOI: 10.3109/00016356309011240.

19. Singh NP, McCoy MT, Tice RR, et al. A simple technique for quantitation of low levels of DNA damage in individual cells. Exp Cell Res 1988;175(1):184-191. DOI: 10.1016/0014-4827(88)90265-0.

20. IARC. Betel-quid and areca-nut chewing. Monographs on the evaluation of the carcinogenic risk of chemicals to humans. Lyon, France: International Agency for Research on Cancer; 1985;37:141-202.

21. Waerhaug J. Prevalence of periodontal disease in Ceylon. Association with age, sex, oral hygiene, socioeconomic factors, vitamin deficiencies, malnutrition, betel and tobacco consumption and ethnic group final report. Acta Odontol Scand 1967;25(2):205-231. DOI: $10.3109 / 00016356709028749$.

22. Jeng JH, Lan WH, Hahn LJ, et al. Inhibition of the migration, attachment, spreading, growth and collagen synthesis of human gingival fibroblasts by arecoline a major alkaloid, in vitro. J Oral Pathol Med 1996;25(7):371-375. DOI: 10.1111/j.1600-0714.1996.tb00281.x.

23. Papa S, Skulachev VP. Reactive oxygen species, mitochondria, apoptosis and aging. Mol Cell Biochem 1997;174(1-2):305-319. DOI: 10.1023/A:1006873518427.

24. Sundqvist NJ, Bartschh K, Grafstromr C, et al. Cytotoxic and genotoxic effects of areca-nut related compounds in cultured human buccal epithelial cells. Cancer Res 1989;;49(19):5294-5298.

25. Akhter R, Hassan NM, Aida J, et al. Relationship between betel quid additives and established periodontitis among Bangladeshi subjects. J Clin Periodontol 2008;35(1):9-15. DOI: 10.1111/j.1600051X.2007.01164.x.

26. Ling LJ, Hung SL, Tseng SC, et al. Association between betel quid chewing, periodontal status and periodontal pathogens. Oral Microbiol Immunol 2001;16(6):364-369. DOI: 10.1034/j.1399302x.2001.160608.x.

27. Reichart PA, Schmidtberg W, Scheifele C. Betel chewer's mucosa in elderly Cambodian women. J Oral Pathol Med. 1996;25(7):367-370. DOI: 10.1111/j.1600-0714.1996.tb00280.x.

28. Wyk CW, Olivier A, Miranda CM, et al. Observations on the effect of areca nut extracts onoral fibroblast proliferation. J Oral Pathol Med 1994;23(4):145-148. DOI: 10.1111/j.1600-0714.1994.tb01103.x.

29. Fisher MA, Taylor GW, Tilashalski KR. Smokeless tobacco and severe active periodontal disease, NHANES III. J Dent Res 2005;84(8):705-710. DOI: 10.1177/154405910508400804.

30. Martinez CP, Lorca A, Magan R. Smoking and periodontal disease severity. J Clin Periodontol 1995;22(10):743-749. DOI: 10.1111/j.1600051X.1995.tb00256.x.

31. Axell TE. Oral mucosal changes related to smokeless tobacco usage: research findings in Scandinavia. Eur J Cancer B Oral Oncol 1993;29B(4):299-302. DOI: 10.1016/0964-1955(93)90052-g.

32. Poulson TC, Lindenmuth JE, Greer RO. A comparison of the use of smokeless tobacco in rural and urban teenagers. CA Cancer J Clin 1984;34(5):248-261. DOI: 10.3322/canjclin.34.5.248.

33. Augustine D, Rao RS, Anbu J, et al. In vitro cytotoxic and apoptotic induction effect of earthworm coelomic fluid of Eudrilus eugeniae, Eisenia foetida, and Perionyx excavatus on human oral squamous cell carcinoma-9 cell line. Toxicol Rep 2019;6:347-357. DOI: 10.1016/j. toxrep.2019.04.005. 